\title{
A giant solitary fibrous tumor of the mesentery: a case report and literature review
}

\author{
Kiyotaka Nishida ${ }^{1 *}$, Hideyuki Ubukata ${ }^{1}$, Satoru Konishi ${ }^{1}$, Jiro Shimazaki ${ }^{1}$, Youko Yano ${ }^{2}$, Yukio Morishita ${ }^{2}$ \\ and Takafumi Tabuchi ${ }^{1}$
}

\begin{abstract}
We report on an extremely rare case of a giant solitary fibrous tumor (SFT) of the mesentery in a 65-year-old male who was admitted to our hospital because of lower abdominal pain and abdominal fullness. Computed tomography demonstrated a well-defined solid mass of $25 \times 11 \mathrm{~cm}$ located in the lower abdomen, which was completely resected during surgery. Histopathologically, this lesion had a heterogeneous cell population, mainly comprising spindle cells with fibrous collagen proliferation, and various other cell populations exhibiting patternless growth. Immunohistochemically, the tumor revealed strong and diffuse staining for CD34, bcl-2, and vimentin, and a high mitotic index (seven mitoses per 10 high-power fields). We diagnosed this case as an SFT of the mesentery, which is unusual according to a PubMed search that reported only nine such cases. Our case may be the largest tumor reported to date, and only one retrieved case reported recurrence, although the lesion was exceptionally large with deep invasion. Nonetheless, the lesion in our case was larger than that in the reported case of recurrence and invasive to the ileum. Since surgery, there has been no evidence of recurrence. Hence, we propose that a large SFT and high mitotic index may present risk factors for recurrence. Therefore, long-term careful follow-up is necessary in such cases, although our case exhibited few risk factors for recurrence. A follow-up at 12 months after surgery found no indications of recurrence.
\end{abstract}

Keywords: Malignant, Mesentery, Solitary fibrous tumor

\section{Background}

A solitary fibrous tumor (SFT) is a rare mesenchymal neoplasm which often involves the thoracic cavity (pleura, lung), and less frequently soft tissues and other visceral and parenchymal organs, including the central nervous system [1-3]. Although SFTs are well described in the literature, those arising from the mesentery are very rare. Here, we report on an extremely rare case of a giant solitary fibrous tumor of the mesentery.

\section{Case presentation}

A 65-year-old male with no significant personal or familial medical history was admitted to our hospital 12 months after a previous visit for symptoms of abdominal fullness and lower abdominal pain. On clinical examination, routine blood results were normal, although the tumor marker

\footnotetext{
* Correspondence: kiyo-n@tokyo-med.ac.jp

${ }^{1}$ Department of Gastroenterological Surgery, Tokyo Medical University, Ibaraki Medical Center, 3-20-1 Chuo Ami, Inashiki, Ibaraki 300-0395, Japan Full list of author information is available at the end of the article
}

cancer antigen 19-9 levels (46.4 U/mL; normal level, $37.0 \mathrm{U} / \mathrm{mL}$ ) were slightly elevated, whereas those of carcinoembryonic antigen were not $(2.2 \mathrm{ng} / \mathrm{mL}$; normal level, $<5.0 \mathrm{ng} / \mathrm{mL}$ ). Contrast-enhanced computed tomography demonstrated a $25 \times 11 \mathrm{~cm}$, well-circumscribed, lobulated, heterogeneous mass in the abdominal cavity, which contained several areas of necrosis and calcification (Figure 1). Magnetic resonance imaging demonstrated a well-circumscribed mass with heterogeneous high-signal intensity on T2-weighted imaging (Figure 2). Computed angiotomography demonstrated two feeding arteries inferior to the mesentery and superior mesentery arteries (Figure 3).

We decided to perform surgery and made a midline incision of the abdomen; we resected a $25 \times 13 \mathrm{~cm}$ firm, encapsulated mass from the mesentery of the proximal ileum. Because the tumor invaded part of the proximal ileum, we performed combined local resection of the ileum (about $30 \mathrm{~cm}$ ) to ensure complete removal. 

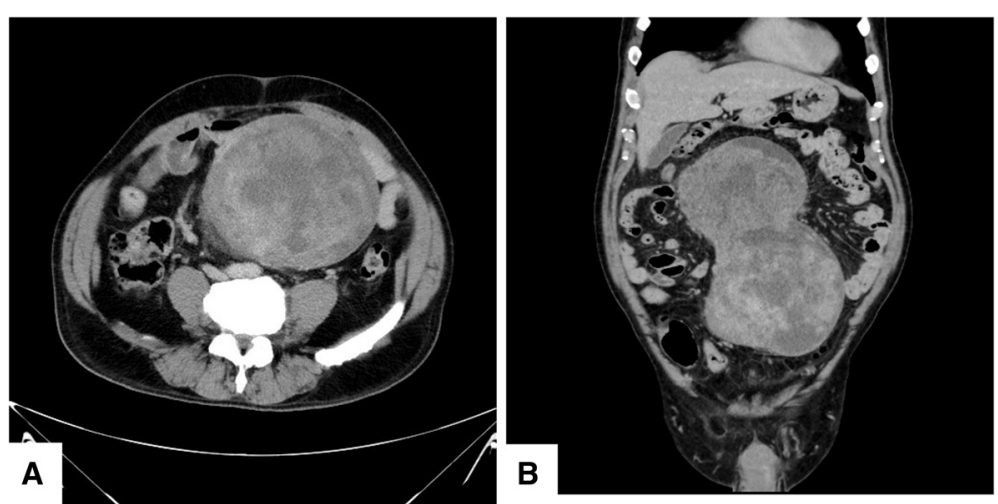

Figure 1 (A) Abdominal computed tomography demonstrated a $25 \times 11 \mathrm{~cm}$, heterogeneous, lobulated mass in the abdominal cavity. (B) Colonal view demonstrated lobulated mass.

Macroscopic examination of the tumor demonstrated a $25.5 \times 13 \times 10 \mathrm{~cm}$, well-defined, firm mass with necrotic foci and a pale cut surface (Figure 4). Following histological examination, the tumor demonstrated necrosis, hypercellularity, cellular atypia, heterogeneous cell populations (comprising mostly of spindle cells that exhibit patternless growth), and fibrous collagen proliferation. Immunohistochemically, the tumor showed strong and diffuse staining for $\mathrm{CD} 34$, bcl-2, and vimentin; other markers, such as pan-cytokeratins, EMA, desmin, alphasmooth muscle actin, and S-100 protein, were negative and had a high mitotic index (seven mitoses per 10 highpower fields (HPF)) (Figure 5). Based on morphological and immunohistochemical findings (a large size, hypercellular areas, cellular atypia, necrotic areas, and high mitotic

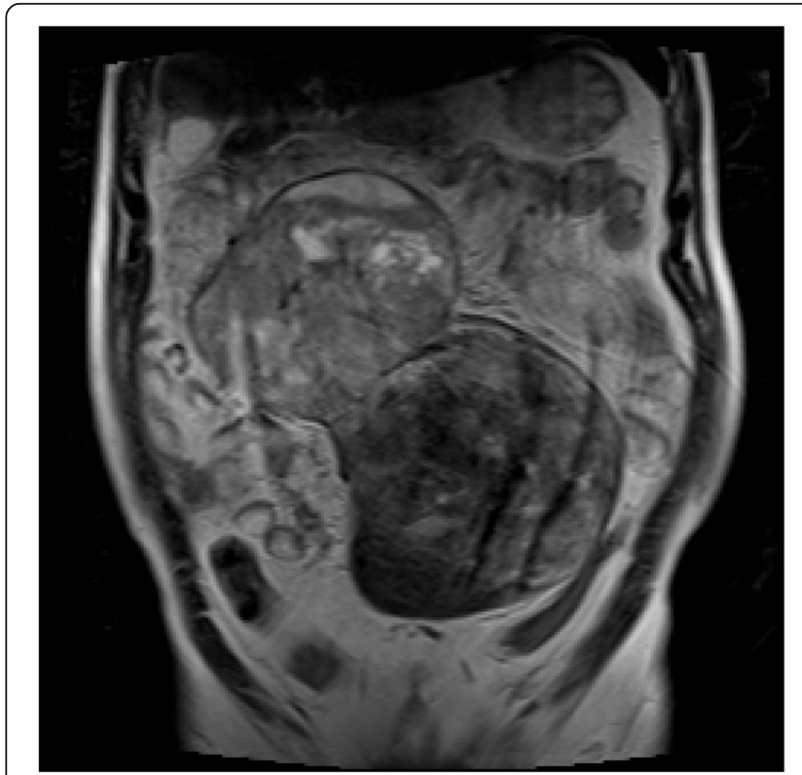

Figure 2 Magnetic resonance imaging demonstrated a well-circumscribed mass with a heterogeneous high signal intensity on T2-weighted imaging. index (seven mitoses per $10 \mathrm{HPF}$ )), a diagnosis of solitary fibrous tumor of the mesentery with malignant potential was determined.

\section{Discussion}

A SFT is a rare mesenchymal spindle cell neoplasm, first described by Klemperer and Rabin in 1931 [1]. Although the etiology of this lesion remains unclear, it has been recently recognized that a SFT may occur in extrapleural locations such as the lung, mediastinum, pericardium, mesentery, peritoneum, extraperitoneal spaces, nose, and paranasal sinuses [4]. However, a SFT arising from the mesentery is unusual.

A search of the PubMed database (http://www.ncbi.nlm. nih.gov/pubmed/) shows reports of only nine cases (Table 1)

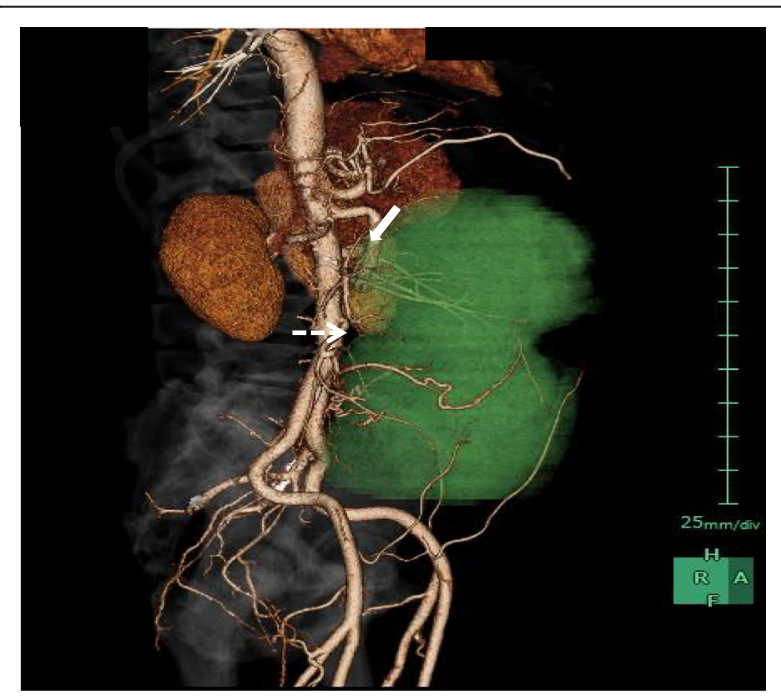

Figure 3 Computed angiotomography demonstrated two feeding arteries, namely the inferior mesenteric artery (arrow) and the superior mesenteric artery (dotted arrow). The green area demonstrates a lobulated tumor. 


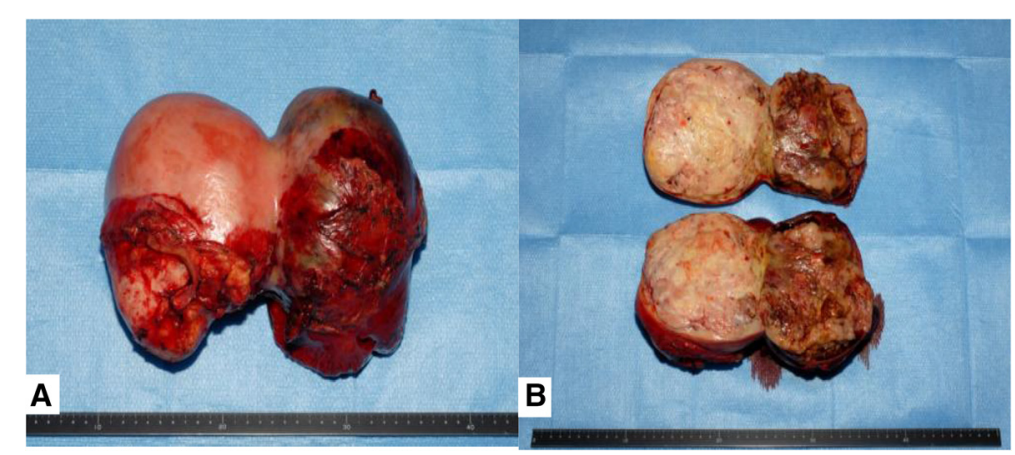

Figure 4 Macroscopic examination of the tumor. (A) The tumor $(25.5 \times 13 \times 10 \mathrm{~cm})$ was a well-defined and firm mass. (B) The tumor demonstrated several areas of necrotic, solid, and bleeding areas.

[5-13]. Of these reports of SFTs of the mesentery retrieved from the literature (Table 1), there was a male prevalence, with a median age of 54 years (range, 33-73 years). Although symptoms of SFTs may be unspecific, they may be related to compression or dislocation of the organs [14]. All cases were treated by surgery, as in our case. Our literature review revealed that the mesenteric SFT resected in our case may be the largest reported to date.

SFTs exhibit a wide spectrum of clinical findings; therefore, surgical resection is necessary to arrive at a final histopathological and immunohistochemical diagnosis [15]. In general, SFTs comprise various cell types, with an abundance of spindle cells exhibiting patternless growth on histopathological examination $[6,15,16]$. Immunohistochemically, SFTs are commonly positive for CD34, bcl-2, and vimentin, but rarely positive for S100 proteins, desmin, actin, and cytokeratins [15]. In our case, the tumor exhibited characteristics of an SFT by both histopathological and immunohistochemical analyses.

Although the majority of SFTs are histopathologically benign, up to $20 \%$ may be malignant [16]. As shown in Table 1, recurrence was reported in only one case (No. 9). In this case, the tumor was very large $(21 \mathrm{~cm})$ with deep invasion to the inferior vena cava and abdominal aorta, and all visible tissue was removed during surgery. In addition, part of the inferior vena cava was resected to separate it
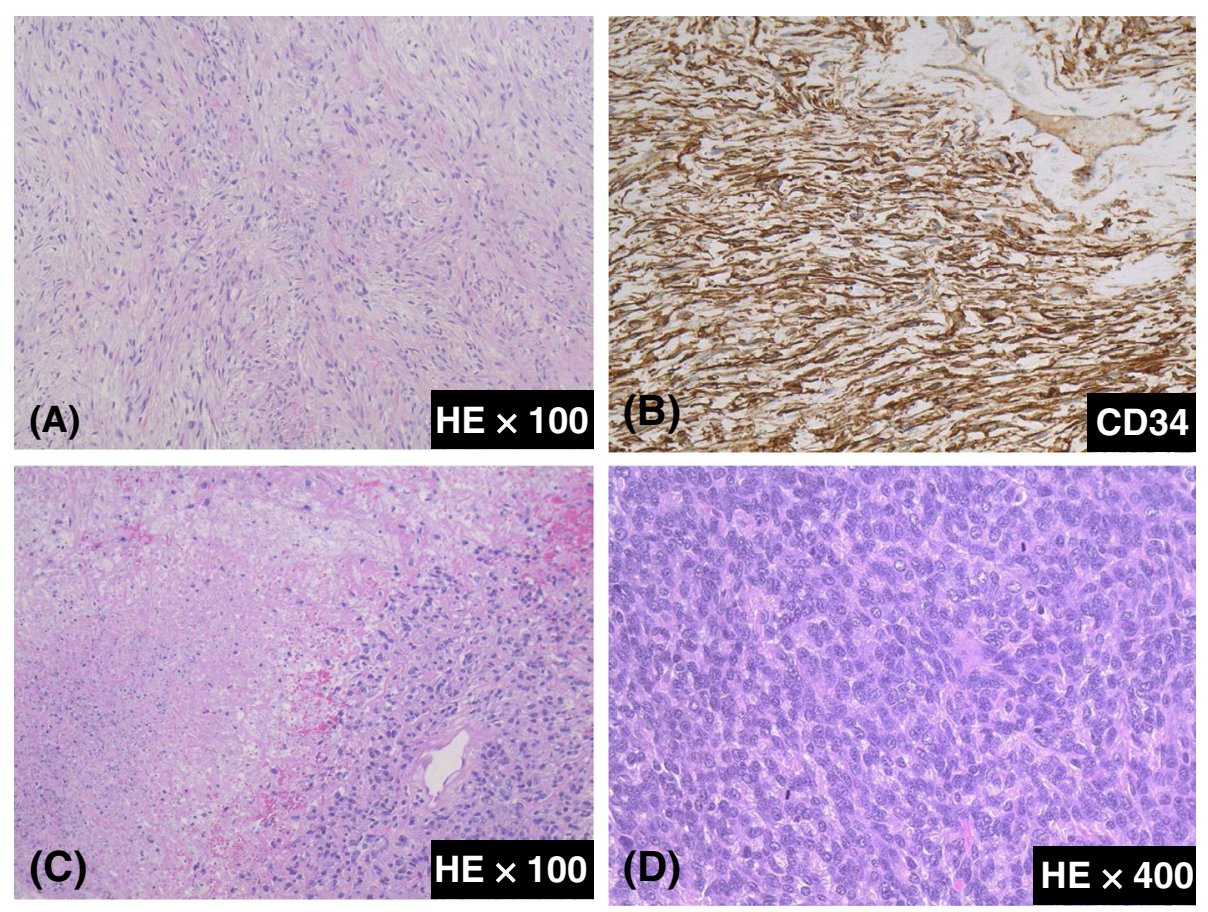

Figure 5 Pathological analysis of the resected specimen. (A) Typical areas of a solitary fibrous tumor. (B) CD34 immunoreactivity. (C) A representative necrotic area. (D) An image demonstrating hypercellular areas with cellular atypia and mitosis (7 mitoses/10 HPF). 
Table 1 Solitary fibrous tumor of mesentery in English literature

\begin{tabular}{|c|c|c|c|c|c|c|c|c|c|}
\hline Case no & Age & Sex & Complaint & Location & Tumor size $(\mathrm{cm})$ & Treatment & Follow-up (months) & Outcome & Reference \\
\hline 1 & 33 & M & NP & Mesentery & NP & Surgery & NP & NP & [5] \\
\hline 2 & 68 & M & Abdominal pain & S-colon mesentery & 18 & Surgery & NP & NP & [6] \\
\hline 3 & 53 & M & Abdominal pain & Distal ileum mesentery & 22 & Surgery & 1 & Alive & [7] \\
\hline 4 & 73 & M & Abdominal pain & Mesentery & 25 & Surgery & NP & NP & [8] \\
\hline 5 & 71 & M & Painless mass & Small bowel mesentery & 15.5 & Surgery & 12 & Alive & [9] \\
\hline 6 & 41 & M & Abdominal Pain & Mesentery & 23 & Surgery & 7 & Alive & [10] \\
\hline 7 & 26 & M & Abdominal fullness & $\begin{array}{l}\text { Proximal ileum } \\
\text { mesentery }\end{array}$ & 12 & Surgery & 18 & Alive & [11] \\
\hline 8 & 36 & M & Abdominal Pain & Rectum mesentery & 15.5 & $\begin{array}{l}\text { Preoperative } \\
\text { RT Surgery }\end{array}$ & NP & NP & [12] \\
\hline 9 & 59 & $\mathrm{~F}$ & Abdominal Pain & Mesentery & 21 & Surgery & 9 & Recurrence & [13] \\
\hline 10 & 65 & M & Abdominal Pain & $\begin{array}{l}\text { Proximal ileum } \\
\text { mesentery }\end{array}$ & 25.5 & Surgery & 12 & Alive & Our case \\
\hline
\end{tabular}

NP, Not provided; M, Male; F, Female.

from the abdominal aorta. Therefore, although complete removal of the tumor may be achieved, recurrence remains a concern. Based on our observations, we propose that the size of a mass may be a risk factor for recurrence.

The malignant variant of a SFT generally comprises a large mass $(>50 \mathrm{~mm}$ in diameter) and the histologic features of malignant behavior are marked by hypercellularity, necrosis, cellular atypia, and a high mitotic index ( $>4$ mitoses per $10 \mathrm{HPF}$ ) [17-19]. All SFTs have the potential to become malignant; thus, gross tumor examination and counting of mitoses are recommended to assess the prognosis of any SFT [20]. In our case, histological analysis revealed characteristics of hypercellularity and invasiveness with nuclear pleomorphism and tissue necrosis. Moreover, this tumor had a high mitotic index (seven mitoses per $10 \mathrm{HPF}$ ). Based on these findings, we considered our case to have malignant potential.

Although the natural history of extrapleural SFTs remains unknown, long-term and careful follow-up may be necessary, especially in cases with a large tumor and a high mitotic index [21]. We followed this case for 12 months after surgery and found no indications of recurrence.

\section{Conclusions}

Here, we reported an extremely rare case of a mesenteric SFT in which the tumor may be the largest reported to date. The tumor was completely removed during surgery; however, careful follow-up is necessary because cases with a large tumor and a high mitotic index may have malignant potential.

\section{Consent}

Written informed consent was obtained from the patient for publication of this case report and all accompanying images. A copy of the written consent form is available for review by the Editor-in-Chief of the journal.

\section{Abbreviations}

CT: Computed tomography; HPF: High-power fields; SFT: Solitary fibrous tumor.

\section{Competing interests}

The authors declare that they have no competing interests.

\section{Authors' contributions}

KN wrote the manuscript. SK and HU performed the surgery. JS and TT drafted the manuscript. All authors read and approved the final version of the manuscript.

\section{Acknowledgments}

The authors thank Enago (www.enago.jp) for editorial assistance.

\section{Author details}

${ }^{1}$ Department of Gastroenterological Surgery, Tokyo Medical University, Ibaraki Medical Center, 3-20-1 Chuo Ami, Inashiki, Ibaraki 300-0395, Japan.

${ }^{2}$ Department of Diagnostic Pathology Division, Tokyo Medical University, Ibaraki Medical Center, 3-20-1 Chuo Ami, Inashiki, Ibaraki 300-0395, Japan.

Received: 14 July 2014 Accepted: 23 December 2014

Published online: 04 February 2015

\section{References}

1. Klemperer P, Robin CB. Primary neoplasms of the pleura. Arch Pathol. 1931;11:385-412.

2. Nascimento AG. Solitary fibrous tumor; a ubiquitous neoplasm of mesenchymal differentiation. Adv Anat Pathol. 1996;3:338-95.

3. Bisceglia M, Dimitri L, Giannatempo G, Carotenuto V, Bianco M, Monte V, et al. Solitary fibrous tumor of the central nervous system: report of an additional 5 cases with comprehensive literature review. Int J Surg Pathol. 2011;19:476-86.

4. Goodlad J, Fletcher C. Solitary fibrous tumor arising at unusual sites: analysis of a series. Histopathology. 1991;19:515-22.

5. Hardisson D, Limeres MA, Jimenez-Heffernan JA, De la Rosa P, Burgos E. Solitary fibrous tumor of the mesentery. Am J Gastroenterol. 1996;91:810-1.

6. Balaji R, Ramachandran K, Somanathan T. A rare case of solitary fibrous tumour of the sigmoid mesocolon: imaging features and review of literature. Cancer Imaging. 2009;9:67-9.

7. Lau MI, Foo FJ, Sissons MC, Kiruparan P. Solitary fibrous tumor of small bowel mesentery: a case report and review of the literature. Tumori. 2010;96:1035-9.

8. Muroni M, Mezzetti G, Noto S. Malignant solitary fibrous tumor originating from the mesentery. Gastroenterology. 2012;142:12-3.

9. Bouhabel S, Leblanc G, Ferreira J, Leclerc YE, Dubé P, Sidéris L. Solitary fibrous tumor arising in the mesentery: a case report. World J Surg Oncol. 2011;9:140.

10. Kudva R, Monappa V, Rao A. Giant solitary fibrous tumor of the mesentery: a rare case. J Cancer Res Ther. 2011;7:376-8.

11. Cantarella F, Graziosi L, Cavazzoni E, Donini A. Small bowel mesentery solitary fibrous tumor. A rare neoplasia in a young male. G Chir. 2012;33:271-3. 
12. Nishikawa T, Takei $Y$, Teshima S, Deie K, Takano $Y$, Tsuno NH, et al. A hypervascular malignant solitary fibrous tumor in the mesentery of the rectum with good response to preoperative radiation therapy. Int Canc Conf J. 2013;2:30-5.

13. Liu Y, Ishibashi H, Sako S, Takeshita K, Li Y, Elnemr A, et al. A giant mesentery malignant solitary fibrous tumor recurring as dedifferentiated liposarcoma - a report of a very rare case and literature review. Gan To Kagaku Ryoho. 2013:40:2466-9.

14. Young RH, Clement PB, McCaughey WT. Solitary fibrous tumors ("fibrous mesotheliomas") of the peritoneum: a report of three cases and a review of the literature. Arch Pathol Lab Med. 1990;114:493-5.

15. Wang $H$, Shen $D$, Hou Y. Malignant solitary tumor in a child: a case report and review of the literature. J Pediatr Surg. 2011;46:E5-9.

16. Gengler C, Guillou L. Solitary fibrous tumor and haemangiopericytoma: evolution of a concept. Histopathology. 2006;48:63-74.

17. Hasegawa T, Mathuno Y, Shimoda T, Hasegawa F, Sano T, Hirohashi S. Extrathoracic solitary fibrous tumors: their histological variability and potentially aggressive behavior. Hum Pathol. 1999;30:1464-73.

18. Collini P, Negri T, Barisella M, Palassini E, Tarantino E, Pastorino U, et al. High-grade sarcomatous overgrowth in solitary fibrous tumors, a clinicopathologic study of 10 cases. Am J Surg Pathol. 2012;36:1202-15.

19. Magro G, Emmanuele C, Lopes M, Vallone G, Greco P. Solitary fibrous tumor of the kidney with sarcomatous overgrowth. Case report and review of the literature. APMIS. 2008;115:1020-5.

20. Fletcher CD, Berman JJ, Corless C, Gorstein F, Lasota J, Longley BJ, et al. Diagnosis of gastrointestinal stromal tumors: a consensus approach. Hum Pathol. 2002;33:459-65.

21. Levy AD, Rimola J, Mehrotra AK, Sobin LH. From the archives of the AFIP: benign fibrous tumors and tumorlike lesions of the mesentery: radiologic-pathologic correlation. Radiographics. 2006;26:245-64.

\section{Submit your next manuscript to BioMed Central and take full advantage of:}

- Convenient online submission

- Thorough peer review

- No space constraints or color figure charges

- Immediate publication on acceptance

- Inclusion in PubMed, CAS, Scopus and Google Scholar

- Research which is freely available for redistribution 